Case Report

\title{
Importance of NAB2-STAT6 Fusion in the Diagnosis of Pancreatic Solitary Fibrous Tumor with Hamartoma-Like Features: A Case Report and Review of the Literature
}

\author{
Kei Tanaka, ${ }^{1,2}$ Takashi Kishimoto, ${ }^{3}$ Masayuki Ohtsuka, ${ }^{2}$ \\ Yukio Nakatani, ${ }^{4}$ and Masaru Miyazaki ${ }^{2}$ \\ ${ }^{1}$ Department of Surgery, Kensei General Hospital, 604 Kuwata, Sakuragawa, Ibaraki 309-1223, Japan \\ ${ }^{2}$ General Surgery, Chiba University Graduate School of Medicine, 1-8-1 Inohana, Chuo-ku, Chiba 260-8670, Japan \\ ${ }^{3}$ Department of Molecular Pathology, Chiba University Graduate School of Medicine, 1-8-1 Inohana, Chuo-ku, Chiba 260-8670, Japan \\ ${ }^{4}$ Diagnostic Pathology, Chiba University Graduate School of Medicine, 1-8-1 Inohana, Chuo-ku, Chiba 260-8670, Japan \\ Correspondence should be addressed to Takashi Kishimoto; tkishi@faculty.chiba-u.jp
}

Received 8 June 2015; Accepted 24 August 2015

Academic Editor: Zsuzsa Schaff

Copyright (C) 2015 Kei Tanaka et al. This is an open access article distributed under the Creative Commons Attribution License, which permits unrestricted use, distribution, and reproduction in any medium, provided the original work is properly cited.

\begin{abstract}
We report a case of pancreatic hamartoma-like solitary fibrous tumor which was differentiated from pancreatic hamartoma with the detection of NAB2-STAT6 fusion, a specific mutation for solitary fibrous tumors. A pancreatic well-demarcated solid nodule, $21 \times 17 \mathrm{~mm}$, of 82-year-old man was surgically enucleated. Microscopic findings were close to a pancreatic hamartoma that consisted of sparsely distributed pancreatic ducts and acini in heavily collagenized fibrous stroma. Neither islet nor peripheral nerve existed in the tumor. The fibroblastic cells in the stroma were immune-positive for CD34, CD99, and bcl-2. But these expressions were not decisive in the differentiation between solitary fibrous tumor and pancreatic hamartoma, because CD34 was positive for both tumors, and CD99 and bcl-2 expressions were not elucidated in the previous cases of pancreatic hamartomas. Thus, we evaluated NAB2-STAT6 fusion. The fibroblastic cells were positive for STAT6 and sequencing analysis revealed the gene fusion between NAB2 exon 4 and STAT6 exon 2, with which the final diagnos is of solitary fibrous tumor was achieved. In conclusion, detection of NAB2STAT6 fusion has a great diagnostic value for pancreatic solitary fibrous tumors with hamartoma-like features.
\end{abstract}

\section{Introduction}

Solitary fibrous tumors (SFTs) are mesenchymal neoplasms, most of which are benign although a part of cases are aggressive with local or distant recurrence. Tumor cells were initially thought to be of mesothelial-cell origin since first report of pleural SFTs was described as localized fibrous mesotheliomas in 1931 [1]. But a series of studies has indicated the fibroblastic or myofibroblastic phenotype of the tumor cells [2-4]. It is now known that SFT can develop in a variety of extrapleural tissues. Among the cases of extrapleural SFT, pancreatic SFT is exceedingly rare; review of the literature yielded 11 prior cases [5-15].

The neoplastic cells in SFTs are spindle or ovoid, and they proliferate in a patternless arrangement characterized by a combination of hyper- and hypocellular areas with varying amounts of collagenized stroma. Hemangiopericytomatous pattern with stag-horn shaped vessels is often observed. Immunohistochemical detection of CD34, CD99, and bcl-2 expressions is commonly employed for the accurate diagnosis of SFT [5]. However, diagnosis is actually challenging in some cases for a wide histological spectrum of this tumor and exceptional immune-phenotype. Recently, NAB2-STAT6 fusion was discovered in SFTs by means of whole-genome and transcriptome sequencing analysis, and following studies have confirmed that NAB2-STAT6 fusion is highly sensitive and specific for SFTs $[16,17]$. The NAB2-STAT6 fusion is associated with high nuclear expression of STAT6, so that the STAT6 immunohistochemistry has become a powerful tool in the diagnosis of SFTs [18-20]. NAB2 codes a transcriptional repressor of the early growth response (EGR) zinc-finger transcription factor, which regulates cell differentiation and 


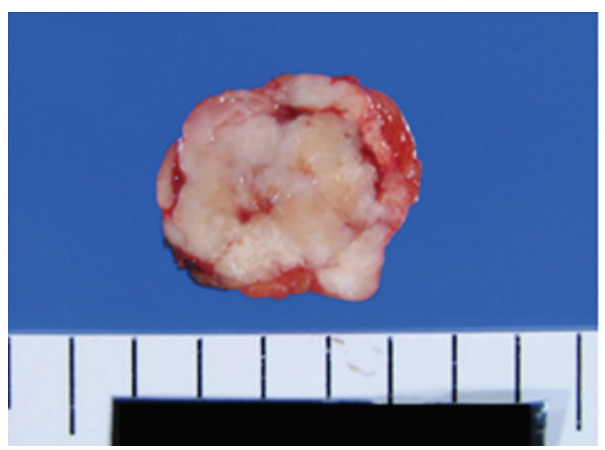

(a)

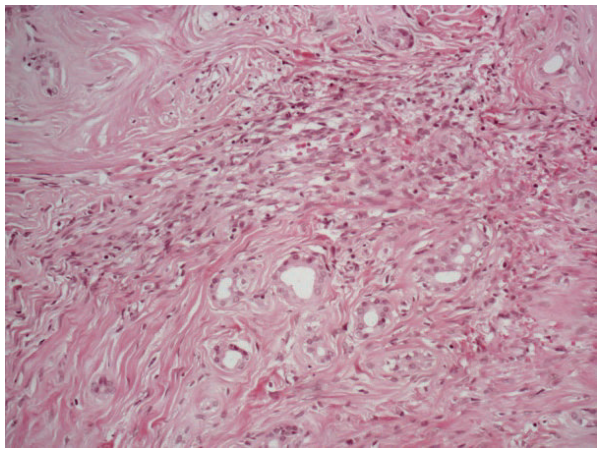

(c)

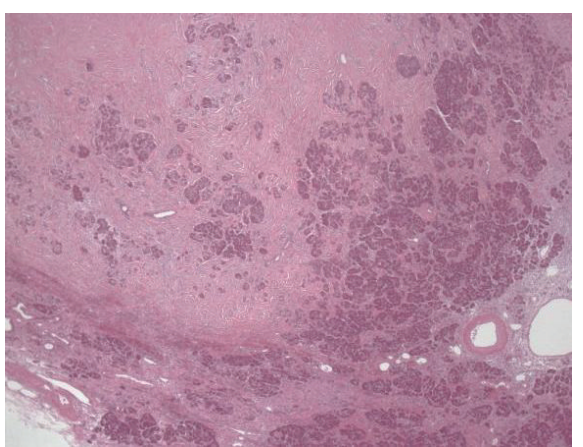

(b)

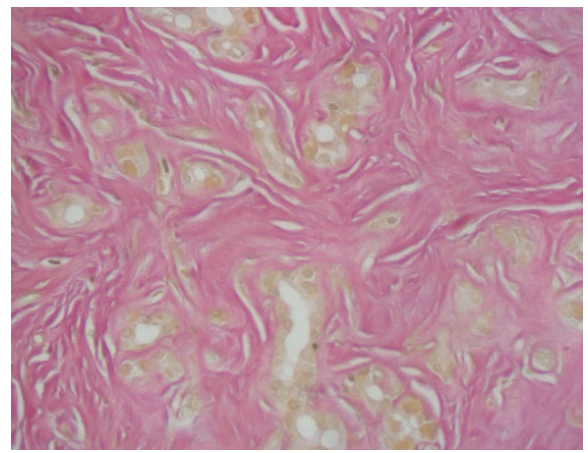

(d)

FIGURE 1: (a) Gross appearance of the surgical specimen showing a well-demarcated and vaguely lobulated ivory-white tumor. (b) Pancreatic parenchyma was haphazardly distributed in the tumor. (c) Spindle cells proliferated in heavily collagenized fibrous stroma. (d) Concentric elastic fibers in the duct walls were not evident with Elastica van Gieson staining.

proliferation. Fusion of activation domain of STAT6 converts $N A B 2$ into a transcriptional activator for EGR families and drives tumorigenic effect $[16,21,22]$.

Pancreatic hamartoma is a rare benign tumor-like nodule. Microscopically, the distorted epithelial components are distributed in fibrous stroma. Hamartomatous properties are supported by those features of cystic dilation of the ducts, lack of both peripheral nerves and well-formed islets of Langerhans, and lack of concentric elastic fibers in the duct wall. Stromal spindle cells are immune-positive for CD34 as well as those in SFTs [23]. The expressions of CD99 and bcl-2 are unknown, because these expressions were not elucidated in the previously reported pancreatic hamartomas [23-39].

We report a case of pancreatic hamartoma-like SFT. The final diagnosis of SFT was dependent on a validation of NAB2-STAT6 fusion, because the features were indistinguishable from the pancreatic hamartoma by microscopic examination with conventional immunohistochemical study.

\section{Case Presentation}

An 82-year-old man was referred to our hospital for further evaluation of a pancreatic and a liver nodule that had been found on abdominal CT in the previous hospital. On admission, the patient had no symptoms. PIVKA-2 was elevated $(84 \mathrm{mAU} / \mathrm{mL})$, but other tumor markers, that is, CEA, CA19-9, and alpha-fetoprotein, were within normal limits. Abdominal CT revealed a mass, $18 \mathrm{~mm}$ in diameter, protruding from the pancreatic tail. The pancreatic mass showed progressive enhancement from the arterial phase to the venous phase on dynamic CT and was hypointense on T2-weighted and diffusion-weighted MR images, which suggested a fibrous tumor. An endoscopic ultrasound with fineneedle aspiration from the pancreatic mass was performed, but paucity of the specimen precluded a diagnosis. At a distance from this nodule, the branch-duct type intraductal papillary-mucinous neoplasm (IPMN) was detected in the preoperative workup. The patient underwent extraction of the pancreatic mass and subsegmentectomy of S8 of the liver. IPMN got a follow-up examination, because it was assessed to be benign on the imaging study. Pathological examination of the surgical specimen of the liver revealed that the liver mass was hepatocellular carcinoma. Eleven months postoperatively, the patient is disease-free and well.

The specimen resected from the pancreas contained a white, well-demarcated solid nodule, measuring $21 \times$ $17 \mathrm{~mm}$, with a homogeneous appearance on its cut surface (Figure 1(a)). Microscopically, pancreatic acini and ductal tissues were sparsely distributed in the heavily collagenized fibrous stroma with fibroblast-like spindle cells. The cellularity of the spindle cells was low in most areas, but there were a few hypercellular areas where the spindle cells haphazardly proliferated (Figures 1(b) and 1(c)). Mitotic figures, necrosis, and vascular invasion were not identified. Neither islet of 


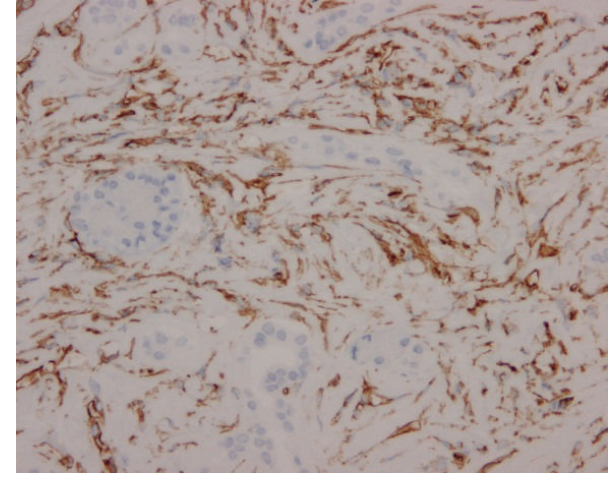

(a)

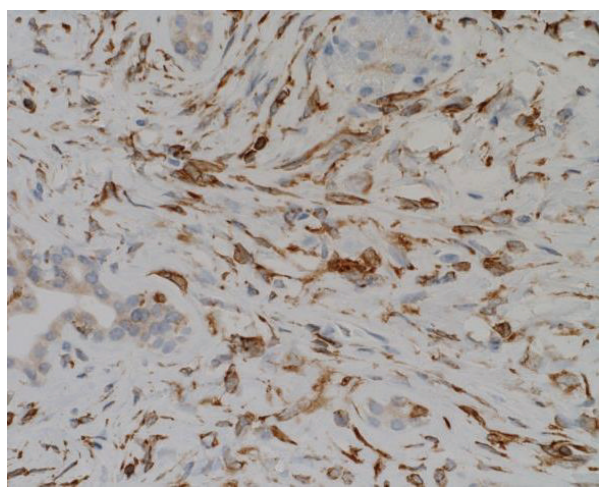

(c)

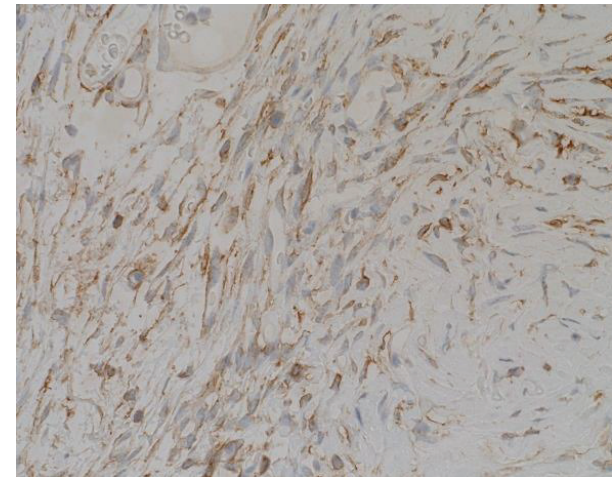

(b)

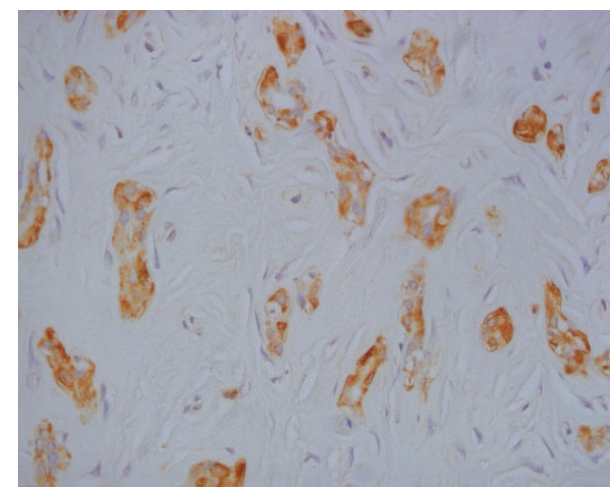

(d)

FIGURE 2: Spindle cells were immune-positive for (a) CD34, (b) CD99, and (c) bcl-2. (d) Ductal epithelia were immune-positive for S-100.

Langerhans nor peripheral nerves existed in the whole area. The stroma was hypovascular and the stag-horn-like vessel was not found. Concentric elastic fibers in the duct walls were not evident with Elastica van Gieson staining (Figure 1(d)). Immunohistochemically, the spindle cells were positive for CD34, CD99, and bcl-2 (Figures 2(a)-2(c)) but negative for $\alpha$ SMA, c-kit, DOG1, desmin, S-100, and calretinin. The ductal epithelia were positive for cytokeratin 7 and S-100 protein (Figure 2(d)). These histological and immunohistochemical findings closely resembled pancreatic hamartomas. For the precise diagnosis, we examined the existence of NAB2-STAT6 fusion in the spindle cells. Immunohistochemical study revealed that STAT6 was highly expressed in the nuclei of the spindle cells (Figure 3(a)). Next, total RNA was extracted from formalin-fixed paraffin embedded tissues with RNeasy FFPE kit (Qiagen, Tokyo, Japan), and RT-PCR was performed to detect NAB2-STAT6 using two forward primers in NAB2, $5^{\prime}$-CAAGTAGCCCGAGAGAGCAC-3' (exon 3) and $5^{\prime}-$ CTGTGTGCCTGCGAAGCC-3' (exon 6), and two reverse primers in STAT6, $5^{\prime}$-GGGAAAGTCGACATAGAGCC-3' (exon 3 ) and $5^{\prime}$-TTCCACGGTCATCTTGATGG-3' (exon 18) [40]. The condition of PCR was initial denaturing at $95^{\circ} \mathrm{C}$ for $10 \mathrm{~min}$, followed by 40 cycles of denaturing at $95^{\circ} \mathrm{C}$ for $30 \mathrm{~s}$, annealing at $55^{\circ} \mathrm{C}$ for $30 \mathrm{~s}$, and extension at $72^{\circ} \mathrm{C}$ for $60 \mathrm{~s}$. The primer set of NAB2 exon 3 and STAT6 exon 3 was only able to amplify the product (Figure $3(\mathrm{~b})$ ). The direct sequence of the product (PRISM 3730 DNA Analyzer, Hokkaido
System Science Co., Ltd., Sapporo, Japan) revealed the gene fusion between NAB2 exon 4 and STAT6 exon 2 (Figure 3(c)). Based on these results, SFT was finally diagnosed for the pancreatic nodule.

\section{Discussion}

We presented a case of hamartoma-like SFT of the pancreas where the final diagnosis was achieved with NAB2-STAT6 fusion. Solitary fibrous tumor is one of the mesenchymal neoplasms where pathological diagnosis is difficult because of broad spectrum of histological appearance. For example, cellular variants of SFTs were previously termed hemangiopericytoma as a different histological entity but hemangiopericytoma is now defined as an obsolete synonym in the latest edition of WHO classification [41]. In the SFT in our patient, components of pancreatic parenchyma were haphazardly entrapped in the tumor, which gave rise to a different diagnosis of pancreatic hamartoma. Yamaguchi and colleagues have studied 9 cases of pancreatic hamartomas and noted that distinct characteristic of pancreatic hamartoma is lack of three components: concentric elastic fibers in duct walls, peripheral nerves, and well-formed islets of Langerhans [23]. They also demonstrated the expression of S-100 protein in ductal epithelia in their cases of pancreatic hamartomas [23]. Our presented pancreatic nodule had these characteristics, although the cystic dilated duct that was observed 


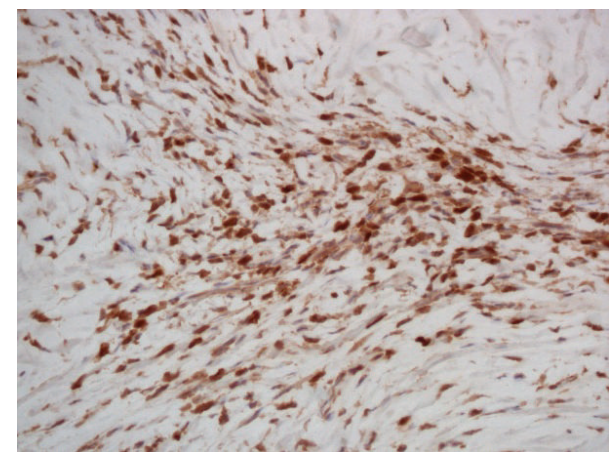

(a)

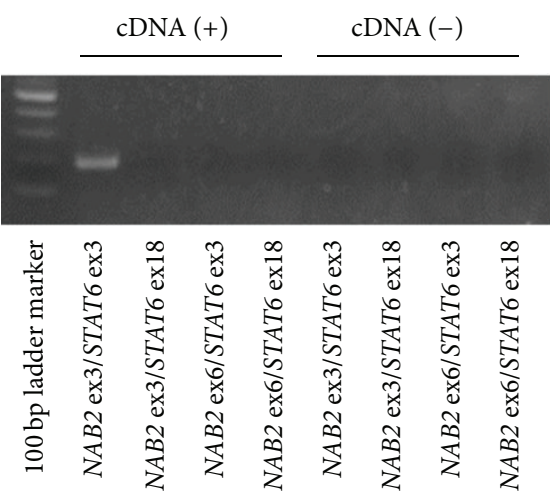

(b)
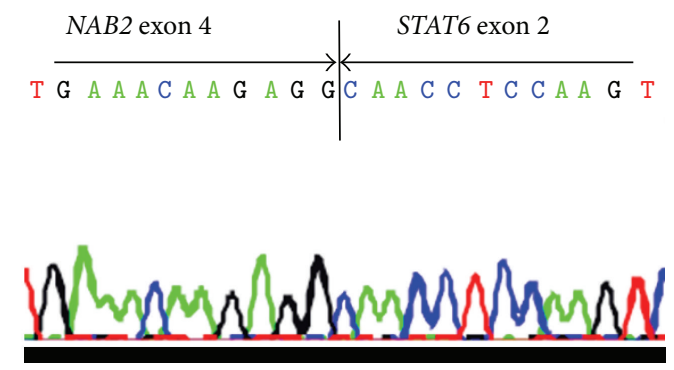

(c)

FIgURE 3: (a) Immunohistochemically, STAT6 was highly expressed in the nuclei of the spindle cells. The results of (b) RT-PCR and (c) sequencing analysis indicated that NAB2 exon 4 fused to STAT6 exon 2.

in some previous cases of pancreatic hamartomas was not evident.

We reviewed the previous cases of pancreatic SFTs (11 cases) and pancreatic hamartomas (29 cases) [23-39] and compared histological features of each disease to get knowledge for the differentiation. As per the result summarized in Table 1, some SFTs had hamartoma-like characters resembling our case, such as entrapped acini (6/7, no description in 4 cases) and lack of islet (2/4, no description in 7 cases). On the other hand, several cases of pancreatic hamartomas lack the characteristics of pancreatic hamartomas, although entrapped acini were observed in all cases; cystic dilation of duct was not observed in 5/26 cases (no description in 3 cases), and islets existed in 6/21 cases (no description in 8 cases).

Most of pancreatic SFTs were diagnosed with the immunohistochemical detection of CD34, CD99, and bcl-2 expressions that have been considered valuable for the pathological diagnosis of SFTs. On the other hand, the diagnosis of the pancreatic hamartoma has been mainly achieved by the microscopic appearance. The most examined molecule was CD34, which was examined in $16 / 29$ cases and was positive in $15 / 16$ cases. The expression of bcl- 2 was examined only in 5/29 cases and was positive in $2 / 5$ cases. There was no previous case of pancreatic hamartomas in which CD99 expression was examined. Thus, immunohistochemical detection of CD34, CD99, and bcl-2 is inefficient in differentiation of hamartoma-like SFTs from pancreatic hamartomas.

Since Robinson and colleagues discovered that NAB2STAT6 gene fusion is the driver mutation of SFTs in 2013,
TABLE 1: Clinicopathological comparison between solitary fibrous tumors and pancreatic hamartomas.

\begin{tabular}{lccc}
\hline & SFT $(n=11)$ & $\begin{array}{c}\text { Hamartoma } \\
(N=29)\end{array}$ & Present case \\
\hline $\begin{array}{l}\text { Age (mean) } \\
\text { Male/female }\end{array}$ & $41-78(51.8)$ & $0-78(45.8)$ & 82 \\
$\begin{array}{l}\text { Size }(\mathrm{cm}) \\
\text { (mean) }\end{array}$ & $2.0-18.5(8.0)$ & $1.0-14(4.5)$ & $\mathrm{M}$ \\
Cystic change & $0 / 4(\mathrm{NE} \mathrm{7)}$ & $21 / 26(\mathrm{NE} 3)$ & $(-)$ \\
$\begin{array}{l}\text { Entrapped } \\
\text { acini }\end{array}$ & $6 / 7(\mathrm{NE} 4)$ & $26 / 26(\mathrm{NE} 3)$ & $(+)$ \\
$\begin{array}{l}\text { Lack of islet } \\
\text { CD34 }\end{array}$ & $2 / 4(\mathrm{NE} \mathrm{7)}$ & $15 / 21(\mathrm{NE} \mathrm{8)}$ & $(+)$ \\
CD99 & $11 / 11$ & $15 / 16(\mathrm{NE} \mathrm{13)}$ & $(+)$ \\
bcl-2 & $6 / 7(\mathrm{NE} 4)$ & $\mathrm{NE} \mathrm{29}$ & $(+)$ \\
\hline
\end{tabular}

SFT: pancreatic solitary fibrous tumor; NE: not examined.

the existence of NAB2-STAT6 fusion became a diagnostic hallmark of SFTs [16]. The following studies based on this discovery have elucidated the usefulness of immunohistochemical detection of nuclear localization of STAT6 as reliable marker for the diagnosis of SFTs [18-20]. Several variants of NAB2-STAT6 have been detected; exon 2, 4, 6, or 7 of NAB2 is fused to exon $2,3,5,6,17$, or 18 of STAT6 $[16,42]$. The presented case had the NAB2 exon 4-STAT6 exon 2 fusion. Akaike and colleagues have studied the variation of NAB2-STAT6 fusion compared with clinicopathologic 
features and showed that the NAB2 exon 4-STAT6 exon 2 genotype is significantly associated with less aggressive phenotype [42]. Although the existence of NAB2-STAT6 fusion in pancreatic hamartomas is unknown, proliferation of cells with driver gene mutation highly indicates the neoplastic property. Thus, we advocate the idea that evaluation of NAB2STAT6 fusion is most informative in the diagnosis of SFTs and is indispensable for differentiation of hamartoma-like SFTs from true pancreatic hamartomas.

In summary, we described a case of pancreatic SFT with hamartoma-like feature. The evaluation of NAB2-STAT6 fusion was of great importance in the diagnosis, especially in the differentiation of a pancreatic hamartoma.

\section{Conflict of Interests}

The authors declare that there is no conflict of interests regarding the publication of this paper.

\section{References}

[1] P. Klemperer and B. R. Caleman, "Primary neoplasms of the pleura: a report of five cases," Archives of Pathology, vol. 11, pp. 385-412, 1931.

[2] S. H. Sung, J.-W. Chang, J. Kim, K. S. Lee, J. Han, and S. I. Park, "Solitary fibrous tumors of the pleura: surgical outcome and clinical course," Annals of Thoracic Surgery, vol. 79, no. 1, pp. 303-307, 2005.

[3] F. J. Hernandez and B. B. Fernandez, "Localized fibrous tumors of pleura: a light and electron microscopic study," Cancer, vol. 34, no. 5, pp. 1667-1674, 1974.

[4] M. Al-Izzi, N. P. Thurlow, and B. Corrin, "Pleural mesothelioma of connective tissue type, localized fibrous tumour of the pleura, and reactive submesothelial hyperplasia. An immunohistochemical comparison," Journal of Pathology, vol. 158, no. 1, pp. 41-44, 1989.

[5] J. Lüttges, T. Mentzel, G. Hübner, and G. Klöppel, “Solitary fibrous tumour of the pancreas: a new member of the small group of mesenchymal pancreatic tumours," Virchows Archiv, vol. 435, no. 1, pp. 37-42, 1999.

[6] H. Miyamoto, D. A. Molena, L. O. Schoeniger, and H. Xu, "Solitary fibrous tumor of the pancreas: a case report," International Journal of Surgical Pathology, vol. 15, no. 3, pp. 311-314, 2007.

[7] H.-J. Kwon, J. H. Byun, J. Kang, H. P. Seong, and M.-G. Lee, "Solitary fibrous tumor of the pancreas: imaging findings," Korean Journal of Radiology, vol. 9, pp. S48-S51, 2008.

[8] V. D. Srinivasan, J. D. Wayne, M. S. Rao, and D. L. Zynger, "Solitary fibrous tumor of the pancreas: case report with cytologic and surgical pathology correlation and review of the literature," Journal of the Pancreas, vol. 9, no. 4, pp. 526-530, 2008.

[9] K. Chatti, K. Nouira, M. Ben Reguigua et al., "Solitary fibrous tumour of the pancreas. À case report," Gastroentérologie Clinique et Biologique, vol. 30, no. 2, pp. 317-319, 2006.

[10] H. Ishiwatari, T. Hayashi, M. Yoshida et al., "A case of solitary fibrous tumor of the pancreas," Nippon Shokakibyo Gakkai Zasshi, vol. 106, no. 7, pp. 1078-1085, 2009.

[11] Y. Sugawara, S. Sakai, S. Aono et al., "Solitary fibrous tumor of the pancreas," Japanese Journal of Radiology, vol. 28, no. 6, pp. 479-482, 2010.
[12] L. A. M. Santos, V. M. Santos, O. C. G. Oliveira, and M. de Marco, "Solitary fibrous tumour of the pancreas: a case report," Anales del Sistema Sanitario de Navarra, vol. 35, no. 1, pp. 133$136,2012$.

[13] A. Tasdemir, I. Soyuer, A. Yurci, I. Karahanli, and H. Akyildiz, "A huge solitary fibrous tumor localized in the pancreas: a young women," Journal of the Pancreas, vol. 13, no. 3, pp. 304-307, 2012.

[14] J.-W. Chen, T. Lü, H.-B. Liu et al., "A solitary fibrous tumor in the pancreas," Chinese Medical Journal, vol. 126, no. 7, pp. 1388$1389,2013$.

[15] A. Gardini, A. Dubini, L. Saragoni, F. Padovani, and D. Garcea, "Benign solitary fibrous tumor of the pancreas: a rare location of extra-pleural fibrous tumor. Single case report and review of the literature," Pathologica, vol. 99, no. 1, pp. 15-18, 2007.

[16] D. R. Robinson, Y.-M. Wu, S. Kalyana-Sundaram et al., "Identification of recurrent NAB2-STAT6 gene fusions in solitary fibrous tumor by integrative sequencing," Nature Genetics, vol. 45 , no. 2, pp. 180-185, 2013.

[17] J. Chmielecki, A. M. Crago, M. Rosenberg et al., "Wholeexome sequencing identifies a recurrent NAB2-STAT6 fusion in solitary fibrous tumors," Nature Genetics, vol. 45, no. 2, pp. 131-132, 2013.

[18] A. Yoshida, K. Tsuta, M. Ohno et al., "STAT6 immunohistochemistry is helpful in the diagnosis of solitary fibrous tumors," American Journal of Surgical Pathology, vol. 38, no. 4, pp. 552$559,2014$.

[19] C. Koelsche, L. Schweizer, M. Renner et al., "Nuclear relocation of STAT6 reliably predicts NAB2-STAT6 fusion for the diagnosis of solitary fibrous tumour," Histopathology, vol. 65, no. 5, pp. 613-622, 1991.

[20] L. A. Doyle, M. Vivero, C. D. M. Fletcher, F. Mertens, and J. L. Hornick, "Nuclear expression of STAT6 distinguishes solitary fibrous tumor from histologic mimics," Modern Pathology, vol. 27, no. 3, pp. 390-395, 2014.

[21] R. Srinivasan, G. M. Mager, R. M. Ward, J. Mayer, and J. Svaren, "NAB2 represses transcription by interacting with the CHD4 subunit of the nucleosome remodeling and deacetylase (NuRD) complex," The Journal of Biological Chemistry, vol. 281, no. 22, pp. 15129-15137, 2006.

[22] J. Svaren, B. R. Sevetson, E. D. Apel, D. B. Zimonjic, N. C. Popescu, and J. Milbrandt, "NAB2, a corepressor of NGFI-A (Egr-1) and Krox20, is induced by proliferative and differentiative stimuli," Molecular and Cellular Biology, vol. 16, no. 7, pp. 3545-3553, 1996.

[23] H. Yamaguchi, S. Aishima, Y. Oda et al., "Distinctive histopathologic findings of pancreatic hamartomas suggesting their 'hamartomatous' nature: a study of 9 cases," American Journal of Surgical Pathology, vol. 37, no. 7, pp. 1006-1013, 2013.

[24] P. P. Anthony, R. G. Faber, and R. C. G. Russell, "Pseudotumours of the pancreas," British Medical Journal, vol. 1, article 814, 1977.

[25] T. B. Burt, V. R. Condon, and M. E. Matlak, "Fetal pancreatic hamartoma," Pediatric Radiology, vol. 13, no. 5, pp. 287-289, 1983.

[26] M. J. Flaherty and D. R. Benjamin, "Multicystic pancreatic hamartoma: a distinctive lesion with immunohistochemical and ultrastructural study," Human Pathology, vol. 23, no. 11, pp. 1309-1312, 1992.

[27] J. R. Izbicki, W. T. Knoefel, J. Muller-Hocker, and H. K. Mandelkow, "Pancreatic hamartoma: a benign tumor of the pancreas," The American Journal of Gastroenterology, vol. 89, no. 8, pp. 1261-1262, 1994. 
[28] S. S. Wu, H. I. Vargas, and S. W. French, "Pancreatic hamartoma with Langerhans cell histiocytosis in a draining lymph node," Histopathology, vol. 33, no. 5, pp. 485-487, 1998.

[29] C. D. McFaul, L. J. Vitone, F. Campbell et al., "Pancreatic hamartoma," Pancreatology, vol. 4, no. 6, pp. 533-537, 2004.

[30] U. Pauser, M. T. S. da Silva, J. Placke, D. S. Klimstra, and G. Klöppel, "Cellular hamartoma resembling gastrointestinal stromal tumor: a solid tumor of the pancreas expressing c-kit (CD117)," Modern Pathology, vol. 18, no. 9, pp. 1211-1216, 2005.

[31] U. Pauser, M. Kosmahl, B. Krušlin, D. S. Klimstra, and G. Klöppel, "Pancreatic solid and cystic hamartoma in adults: characterization of a new tumorous lesion," American Journal of Surgical Pathology, vol. 29, no. 6, pp. 797-800, 2005.

[32] S. Nagata, K. Yamaguchi, T. Inoue et al., "Solid pancreatic hamartoma," Pathology International, vol. 57, no. 5, pp. 276-280, 2007.

[33] M. Thrall, J. Jessurun, E. B. Stelow et al., "Multicystic adenomatoid hamartoma of the pancreas: a hitherto undescribed pancreatic tumor occurring in a 3-year-old boy," Pediatric and Developmental Pathology, vol. 11, no. 4, pp. 314-320, 2008.

[34] D. Sampelean, M. Adam, V. Muntean, B. Hanescu, and I. Domsa, "Pancreatic hamartoma and SAPHO syndrome: a case report," Journal of Gastrointestinal and Liver Diseases, vol. 18, no. 4, pp. 483-486, 2009.

[35] F. Kawakami, M. Shimizu, H. Yamaguchi et al., "Multiple solid pancreatic hamartomas: a case report and review of the literature," World Journal of Gastrointestinal Oncology, vol. 4, pp. 202-206, 2012.

[36] H.-H. Kim, C.-K. Cho, Y.-H. Hur et al., "Pancreatic hamartoma diagnosed after surgical resection," Journal of the Korean Surgical Society, vol. 83, no. 5, pp. 330-334, 2012.

[37] R. Sueyoshi, T. Okazaki, G. J. Lane, A. Arakawa, T. Yao, and A. Yamataka, "Multicystic adenomatoid pancreatic hamartoma in a child: case report and literature review," International Journal of Surgery Case Reports, vol. 4, no. 1, pp. 1-3, 2013.

[38] P. Addeo, G. Tudor, E. Oussoultzoglou, G. Averous, and P. Bachellier, "Pancreatic hamartoma," Surgery, vol. 156, no. 5, pp. 1284-1285, 2014.

[39] H. Inoue, M. Tameda, R. Yamada et al., "Pancreatic hamartoma: a rare cause of obstructive jaundice," Endoscopy, vol. 46, no. 1, pp. E157-E158, 2014.

[40] R. Vogels, M. Vlenterie, Y. Versleijen-Jonkers et al., "Solitary fibrous tumor-clinicopathologic, immunohistochemical and molecular analysis of 28 cases," Diagnostic Pathology, vol. 9, no. 1, article 224, 2014.

[41] C. D. M. Fletcher, J. A. Bridge, P. C. W. Hogendoom et al., WHO Classification of Tumours of Soft Tissue and Bone, IARC, Lyon, France, 2013.

[42] K. Akaike, A. Kurisaki-Arakawa, K. Hara et al., "Distinct clinicopathological features of NAB2-STAT6 fusion gene variants in solitary fibrous tumor with emphasis on the acquisition of highly malignant potential," Human Pathology, vol. 46, no. 3, pp. 347-356, 2015. 


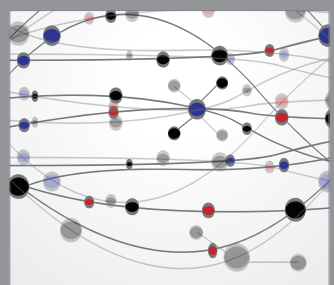

The Scientific World Journal
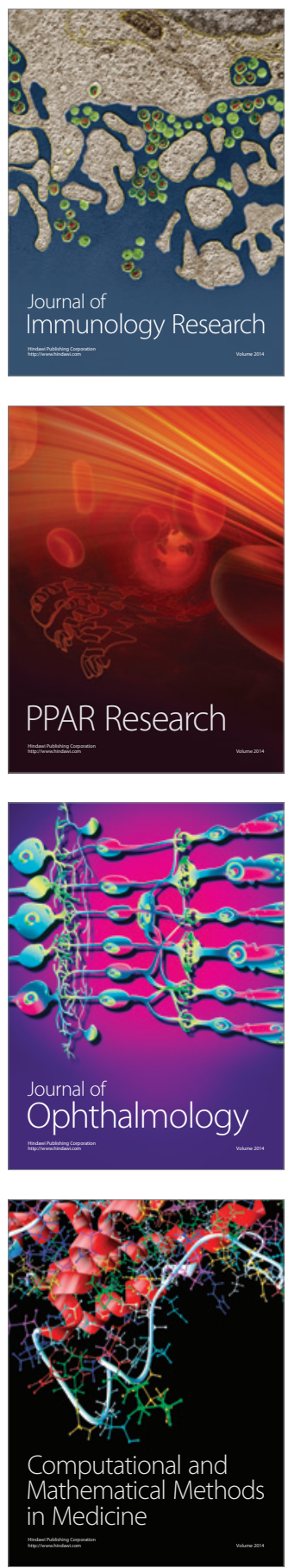

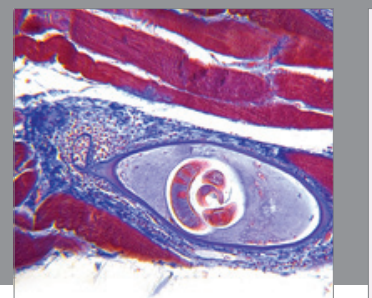

Gastroenterology

Research and Practice
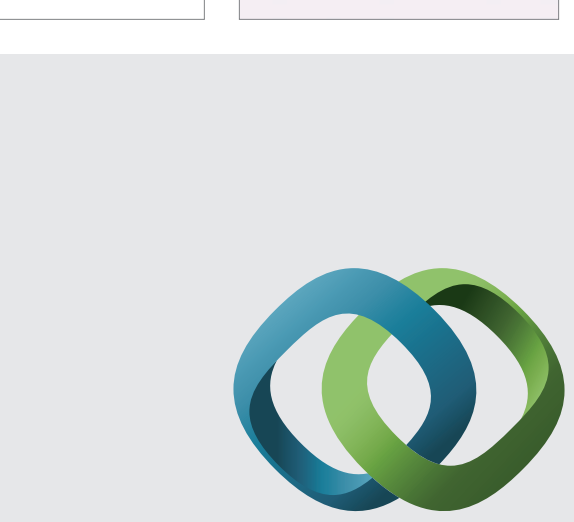

\section{Hindawi}

Submit your manuscripts at

http://www.hindawi.com
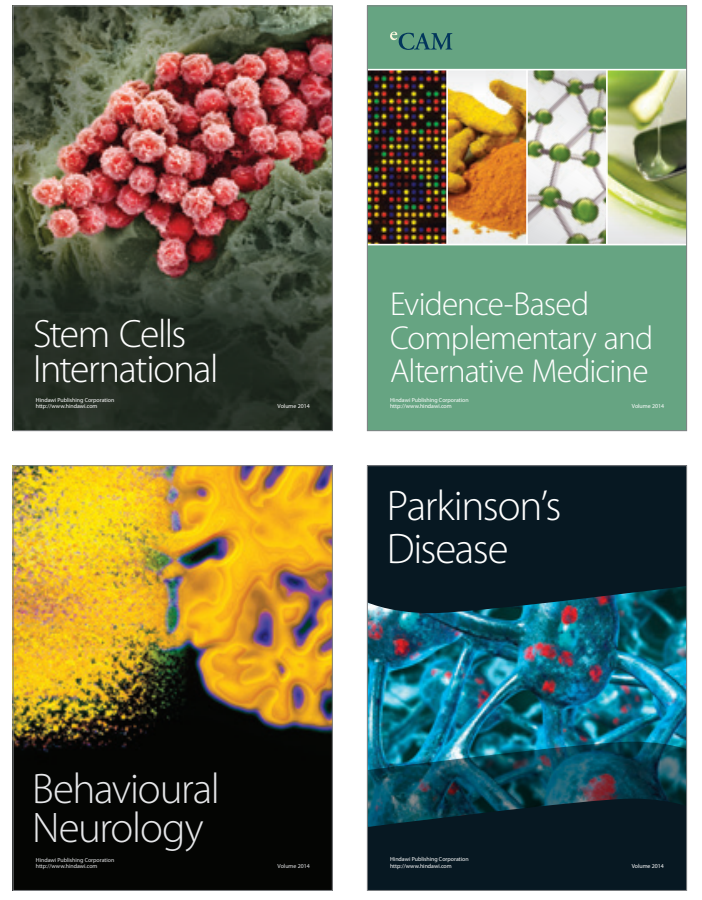
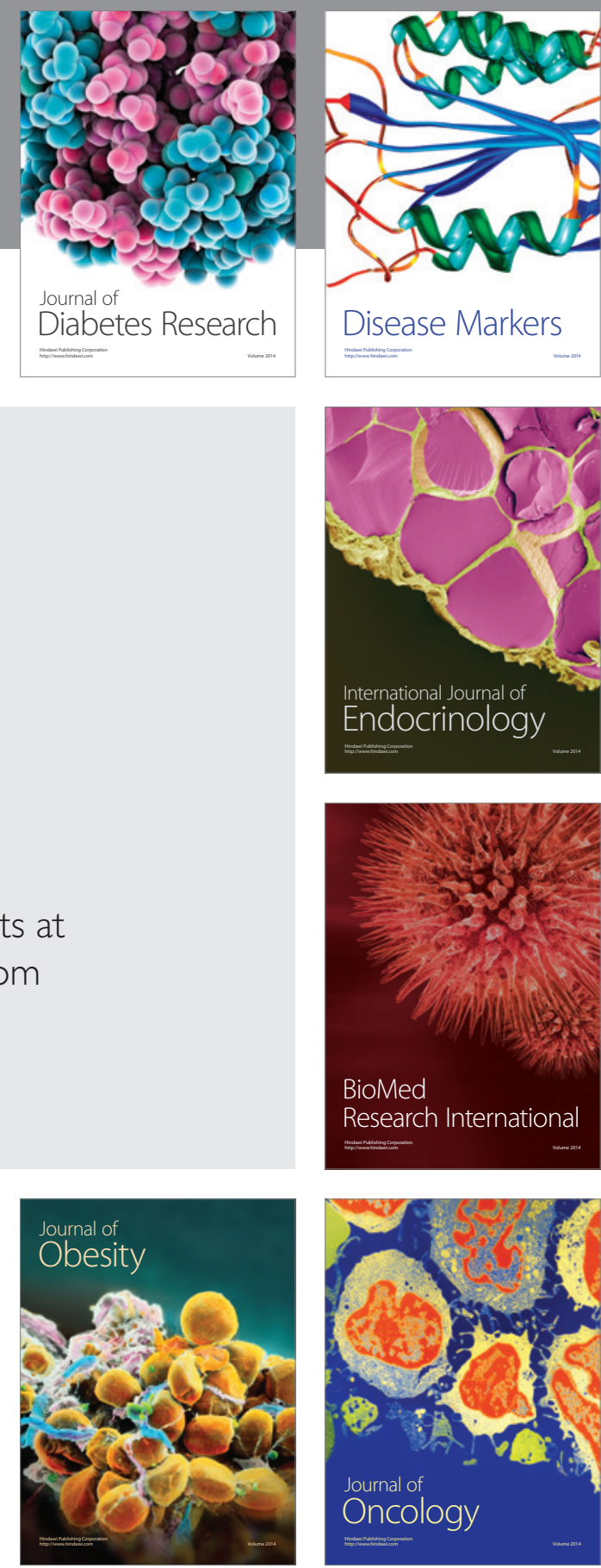

Disease Markers
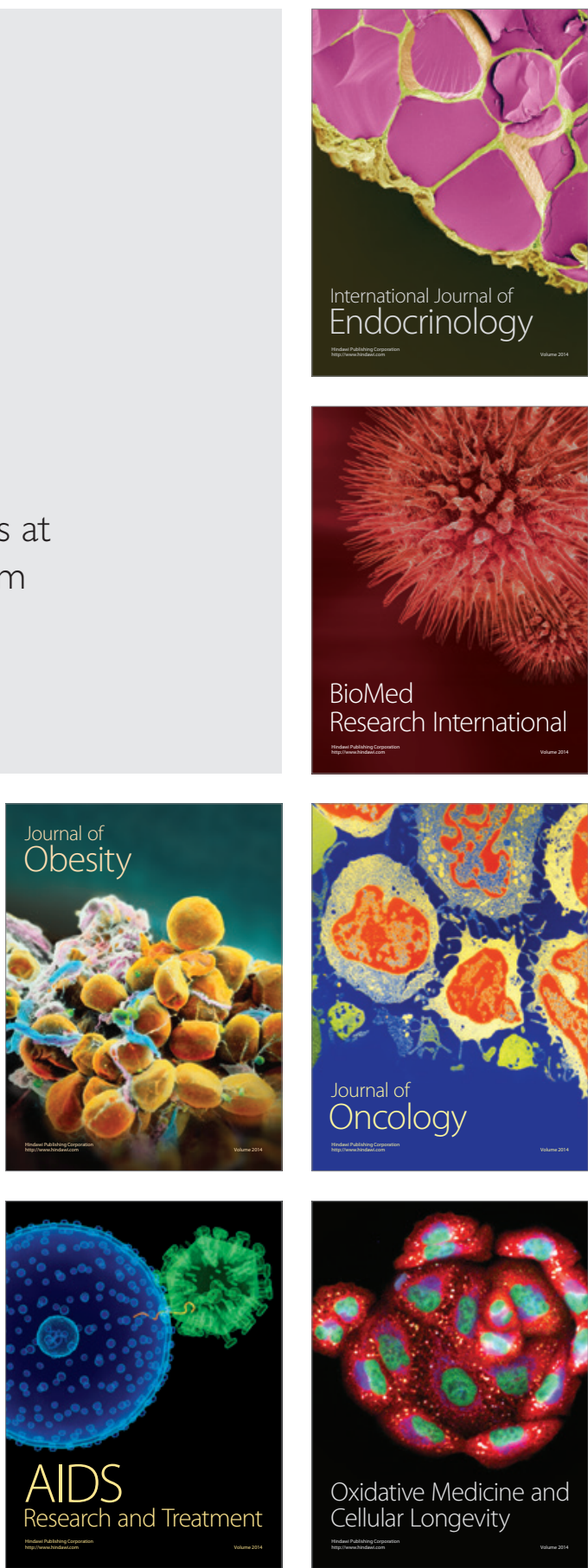